\title{
ANALISIS PENGENDALIAN PERSEDIAAN BAHAN BAKU \\ DENGAN METODE ECONOMIC ORDER QUANTITY DAN KANBAN PADA PT ADYAWINSA STAMPING INDUSTRIES
}

\author{
Noor Apriyani, Ahmad Muhsin \\ Jurusan Teknik Industri, FTI Universitas Pembangunan Nasional "Veteran" Yogyakarta \\ Jl. Babarsari 2 Tambakbayan, Yogyakarta, 55281 \\ Telp. (0274) 485363 Fak : (0274) 486256
}

\begin{abstract}
Abstrak
PT Adyawinsa Stamping Industries merupakan salah satu perusahaan yang tergabung dalam Adyawinsa Dinamika Group dimana perusahaan ini bergerak dalam bidang otomotif di Indonesia. PT Adyawinsa Stamping Industries melakukan pencetakan, sub-assembly suku cadang untuk kendaraan roda empat yang telah berdiri sejak 2005. Dalam menjalankan produksinya, PT Adyawinsa Stamping Industries sering terjadi kondisi jumlah persediaan bahan baku mendekati stockout terutama pada material bagian mobil dengan nomor seri AA-437 (58371-BZ130). Hal ini dikarenakan adanya ketidakpastian dalam menentukan jumlah pembelian bahan baku yang optimal dan keterlambatan pemesanan bahan baku.
\end{abstract}

Economic Order Quantity (EOQ) merupakan suatu teknik untuk melakukan pengadaan persediaan bahan baku pada suatu perusahaan yang menentukan berapa jumlah pesanan yang ekonomis untuk setiap kali pemesanan dengan frekuensi yang telah ditentukan serta kapan dilakukan pemesanan kembali. Metode ini bertujuan untuk meminimalkan Total Inventory Cost. Penggunaan metode ini juga dapat menekan biaya-biaya persediaan sehingga efesiensi persediaan berjalan dengan baik dan dapat tercapai jumlah unit pemesanan yang optimal dengan menekan biaya seminimal mungkin.

Metode EOQ memberikan kuantitas pemesanan yang paling optimal dengan mengeluarkan biaya per periode pada bahan baku produk AA-437 sebesar Rp 1.377.668.782,00 sedangkan untuk metode Kanban sebesar Rp 1.396.108.693,00. Persediaan pengaman apabila menggunakan metode EOQ sebesar 1582 unit sedangkan menggunakan metode Kanban sebesar 110 unit.

Keywords : Stock out, EOQ, TIC, Kanban

\section{PENDAHULUAN}

PT Adyawinsa Stamping Industries merupakan salah satu perusahaan yang tergabung dalam Adyawinsa Dinamika Group dimana perusahaan ini bergerak dalam bidang otomotif di Indonesia. PT Adyawinsa Stamping Industries melakukan pencetakan, sub-assembly suku cadang untuk kendaraan roda empat yang telah berdiri sejak 2005. Dalam menjalankan produksinya, PT Adyawinsa Stamping Industries menganut sistem produksi mass production and customization. Pada proses produksi dapat dilakukan setelah adanya kesepakatan antara pihak konsumen terhadap perusahaan mengenai spsesifikasi produk dan jumlah yang akan diproduksi untuk memenuhi kebutuhan konsumen. Setelah mengetahui jumlah permintaan dari konsumen, maka perusahaan dapat membuat perencanaan proses produksi. Pada saat memproduksi suatu produk hal yang paling utama yaitu perencanaan bahan baku dan melakukan pengendalian terhadap persediaan bahan baku.

Departemen Material Planning Control (MPC) merupakan departemen yang memiliki tugas yaitu melaksanakan pekerjaan dibidang perencanaan dan pengendalian material perusahaan meliputi, menyediakan bahan baku, mengendalikan jumlah persediaan, serta sistem penyimpanan dan mangatur barang masuk maupun keluar dari gudang. Pengendalian jumlah persediaan salah satu faktor terpenting dalam mengoptimalkan persediaan. Pegendalian Persediaan merupakan kegiatan dalam mengelola persediaan agar sesuai dengan kebutuhan dan tetap stabil. Hal 
ini bertujuan untuk menghindari terjadinya penumpukan maupun menjaga agar tidak kehabisan stock pada saat material tersebut di butuhkan sehingga proses produksi tetap berjalan dengan lancar dan tidak mengalami kerugian akibat kehabisan stock tersebut.

Pada sistem pengendalian persediaan pada PT Adyawinsa Stamping Industries menggunakan kebijakan Safety stock dengan maksimal 5 hari dan minimal 3 hari. Apabila material datang, maka masuk ke gudang bahan baku, sedangkan untuk menggunakan material menggunakan sistem First In First Out (FIFO). Berdasarkan kartu kanban dari bagian produksi maka terlampir surat permintaan material, pada bagian MPC akan menyiapkan sesuai jumlah permintaan dan metrial akan dikeluarkan sebagai bukti transaksi untuk mengurangi stockout. Pada sistem saat ini masih sering terjadi kondisi jumlah persediaan bahan baku mendekati stockout terutama pada material bagian mobil dengan nomor seri AA-437 (58371-BZ130).

Hal ini dikarenakan adanya ketidakpastian dalam menentukan jumlah pembelian bahan baku yang optimal dan keterlambatan pemesanan bahan baku karena tidak memiliki penjadwalan pemesanan yang tepat, hanya saja apabila stock kurang dari Safety stock minimum maka dilakukan pemesanan. Selama ini perusahaan menanggulangi minimnya persediaan material tersebut apabila sewaktu-waktu dibutuhkan, dengan menggunakan material yang ada dengan spesifikasi yang sama sesuai dengan kebutuhan produk. Akan tetapi penggunaan material pengganti ini harus melakukan proses cutting terlebih dahulu sesuai ukuran yang diminta dan sewaktu-waktu material pengganti tidak dapat digunakan karena mengingat akan kebutuhan produk utamanya harus terpenuhi lebih dulu. Sehingga apabila hal ini terus terjadi dan tidak diantisipasi dengan baik maka menimbulkan terjadinya kekurangan bahan baku dan dapat menyebabkan utilitas mesin menurun, pekerja yang menganggur, dan menyebabkan perusahaan harus menanggung biaya karena terhambatnya proses produksi serta pendistribusian ke konsumen. Sedangkan apabila terjadi kelebihan stock dapat menimbulkan permasalahan seperti kerusakan material sebab penyimpanan yang terlalu lama dan besarnya biaya penyimpanan akibatnyanilai total cost (TC) juga ikut meningkat.
Dengan data permintaan pada periode sebelumnya, lead time, kapasitas palet, Safety Stock, biaya simpan maupun biaya pesan, dan total biaya untuk masing-masing produk, maka dapat dilakukan pengendalian persediaan untuk mengurangi overload maupun kekurangan material dengan menggunakan metode EOQ (Economic Order Quantity) dan metode Kanban. Penerapan teknik EOQ dalam suatu perusahaan dapat memberikan kuantitas pemesanan yang akurat agar tidak terjadi kekosongan stock. Sedangkan pada metode Kanban perusahaan dapat menarapkan sistem Kanban pemasok atau menggunakan kartu Kanban yang didalamnya memuat informasi yang dibutuhkan perusahaan dalam pemesanan material sesuai dengan kebutuhan. Metodemetode ini dapat mengantisipasi peningkatan pesanan dari konsumen, sehingga produksi berjalan dengan lancar dan permintaan konsumen dapat terpenuhi.

Berdasarkan permasalahan yang telah dipaparkan maka perumusan masalah pada penelitian ini adalah:

1. Bagaimana menentukuan order bahan baku yang optimal pada bahan baku produk AA-0437 (58371-BZ130) dengan metode Eqonomic Order Quantity dan Metode Kanban.

2. Berapa Total Inventory Cost apabila menggunakan metode Eqonomic Order Quantity maupun metode Kanban dalam mengoptimalkan persediaan.

1.3 Batasan Masalah dan Asumsi

Batasan- batasan dalam penelitian ini adalah:

1. Penelitian pada departemen Material Planning Control di PT Adyawinsa Stamping Industries.

2. Penelitian ini membahas tentang persediaan pada departemen Material planning Control di PT Adyawinsa Stamping Industries dan tidak membahas terkait supplier.

3. Penelitian dan analisa hanya dilakukan pada produk bahan baku produk AA0437 berdasarkan data bulan Juli 2016Juni 2017.

4. Analisa dilakukan menggunakan metode Economic Order Quantity dan metode Kanban.

5. Biaya pemesanan yang digunakan adalah biaya yang diperoleh dari hasil wawancara. 
Asumsi - asumsi dalam penelitian ini adalah :

1. Leadtime waktu pengiriman bahan baku konstan.

2. Biaya pemesanan bersifat konstan.

3. Tenaga kerja dan sumber daya lainnya berjalan lancar.

4. Pengiriman bahan baku berjalan dengan lancar sesuai permintaan PT Adyawinsa Stamping Industries.

Berdasarkan pokok permasalahan yang telah dirumuskan pada penelitian ini maka tujuan yang ingin di capai adalah sebagai menentukan kuantitas optimal persediaan dalam meminimasi stockout sebelum waktu penerimaan bahan baku dan overload setelah bahan baku diterima yang dibutuhkan oleh PT Adyawinsa Stamping Industries guna meminimasi biaya bahan baku.

Diharapkan dari penelitian ini apabila tercapai dapat menjadi salah satu pertimbangan dalam menentukan kuantitas yang optimal dalam order bahan baku sehingga tidak terjadi stockout sebelum waktu penerimaan bahan baku dan overload serta mengurangi pengeluaran bahan baku guna mengendalikan persediaan pada wharehouse bahan baku.

Dalam suatu perusahaan baik itu perusahaan manufaktur maupun perusahaan jasa, persediaan memegang peran penting dalam operasi bisnis. Persediaan sebagai bekal untuk memulainya suatu produksi. Dalam setiap perusahaan masing-masing memliki persediaan yang berbeda beda tergantung jumlah kebutuhan maupun jenis persediaan yang diinginkan. Pada perusahaan manufaktur persediaan terrdiri dari tiga jenis persediaan yaitu persediaan bahan baku atau bahan mentah (Inventory of raw material), persediaan barang setengah jadi (Inventory of work in process) dan persediaan barang jadi (Inventory of finished goods).

Menurut Prawirosentono (2005), persediaan didefinisikan sebagai kekayaan lancar yang terdapat dalam perusahaan dalam bentuk persediaan bahan mentah/barang (raw material), barang setengah jadi (work in process), dan barang jadi (finishedgoods). Menurut Herjanto (1999) Persediaan adalah bahan atau barang yang disimpan kemudian akan digunakan untuk memenuhi tujuan tertentu, misalnya produksi atau perakitan, untuk suku cadang dari suati peralatan atau mesin. Menurut Nasution (2008) Persediaan adalah sumber daya menganggur (idle recources) yang menunggu proses lebih lanjut. Yang dimaksud dengan proses lanjut tersebut adalah berupa kegiatan produksi pada sistem manufaktur, kegiatan pemasaran pada sistem distribusi ataupun kegiatan konsumsi pada sistem rumah tangga.

Dari beberapa pendapat para ahli, persediaan dapat didefinisikan sebagai suatu kegiatan yang berupa kekayaan lancar perusahaan dalam bentuk persediaan yang dapat disimpan untuk mengantisipasi permintaan konsumen dan sewaktuwaktu akan digunakan dalam proses produksi untuk dioleh lebih lanjut yang memiliki tujuan tertentu. Dari persediaan bahan baku tersebut dapat diolah bahan baku menjadi produk jadi maupun produk setengah jadi untuk memenuhi kebutuhan konsumen.

Siagian (2005) berpendapat bahwa persediaan yang ideal harus memenuhi syarat-syarat sebagai berikut:

a. Peningkatan layanan terhadap pelanggan, melalui pemberian layanan berupa penyediaan bahan atau barang yang dibutuhkan pelanggan (service availability).

b. Penekanan biaya. Persediaan tidak hanya sekedar menyediakan bahan atau barang sesuai kebutuhan saja, tetapi harus mempertimbangkan halhal lain seperti ketepatan waktu, ketepatan mutu, biaya yang ekonomis, dan ketepatan jumlah.

Menurut Herjanto

mengemukakan beberapa fungsi persediaan dalam memenuhi kebutuhan perusahaan sebagai berikut :

1. Menghilangkan risiko keterlambatan pengiriman bahan baku atau barang yang dibutuhkan perusahaan

2. Menghilangkan risiko jika material yang dipesan tidak baik sehingga harus dikembalikan

3. Menghilangkan risiko terhadap kenaikan harga barang atau inflasi

4. Untuk menyimpan bahan baku yang dihasilkan secara musiman sehingga perusahaan tidak akan kesulitan jika bahan itu tidak tersedia di pasaran

5. Mendapatkan keuntungan dari pembelian berdasarkan diskon kuantitas 
6. Memberikan pelayanan kepada pelanggan dengan tersedianya barang yang diperlukan

Dalam pengendalian persediaan, warehouse atau pergudangan berperan penting dalam menyimpan persediaan yang siap di proses lebih lanjut. Warehouse atau pergudangan adalah area atau tempat yang nantinya berfungsi untuk menyimpan bahan baku atau barang untuk produksi maupun barang hasil produksi dalam jumlah dan retang waktu tertentu yang kemudian akan didistribusikan ke lokasi yang diinginkan berdasarkan permintaan. Warehouse Management System atau Sistem Manajemen Pergudangan merupakan kunci utama dalam supply chain, dimana yang menjadi tujuan utama adalah mengontrol segala proses yang terjadi di dalamnya seperti shipping (pengiriman), receiving (penerimaan), putaway (penyimpanan), move (pergerakan), dan picking (pengambilan).

Dalam sistem pergudangan perlu diadakan pengontrolan terhadap keluar masuknya barang sehingga barang-barang persediaan yang terdapat di dalam gudang dapat terdeteksi dan dapat diketahui keberadaannya. Dalam hal ini bagian pergudangan juga bertanggung jawab atas pemesanan kembali barang-barang yang merupakan stock atau persediaan yang harus selalu ada di gudang. Oleh karena itu pengendalian persediaan sangat dibutuhkan pada bagian pergudangan untuk mengendalikan segala kegiatan keluar masuknya barang di gudang.

Peramalan adalah proses untuk memperkirakan beberapa kebutuhan di masa yang akan datang yang meliputi kebutuhan dalam ukuran kuantitas, kualitas, waktu dan lokasi yang dibutuhkan dalam rangka memenuhi permintaan barang ataupun jasa.

WINQSB merupakan salah satu software yang dapat membantu peramalan untuk kebutuhan di masa depan. WINQSB adalah sistem interaktif untuk membantu pengambilan keputusan yang berisi alat yang berguna untuk memecahkan berbagai jenis masalah dalam bidang riset operasi. Sistem ini terdiri dari modul-modul yang berbeda, satu untuk setiap model jenis atau masalah. WINQSB menggunakan mekanisme tampilan jendela seperti Windows, yaitu jendela, menu, toolbar, dll. Oleh karena itu pengelolaan program serupa dengan yang lain menggunakan lingkungan Windows.

Manajemen persediaan berkenaan dengan masalah persediaan tertentu seperti menyeimbangkan biaya pengiriman dan biaya pemesanan dan menentukan kuantitas pesanan optimal (Griffin, 2004). Menurut Margaretha (2007), model kuantitas pemesanan ekonomis (EOQ) merupakan suatu teknik yang dapat menghitung seberapa besar jumlah pesanan yang harus dilakukan. Sugiono (2009) mengatakan bahwa teknik ini merupakan penentuan jumlah pesanan paling ekonomis yang dapat dilakukan apabila persediaan bahan baku bergantung lebih pada satu pemasok sehingga perlu dipertimbangkan jumlah pembelian sesuai dengan kebutuhan proses produksi.

Tujuan yang dicapai perusahaan ialah untuk memaksimasi nilai dari perusahaan, maka diperlukan tindakan yang terarah dalam mengelola persediaan di suatu perusahaannya. Pada persediaan yang sangat banyak memungkinkan dapat memenuhi permintaan konsumen yang tiba-tiba meningkat, akan tetapi persediaan yang terlalu banyak juga dapat menimbulkan pengeluaran modal kerja yang besar pula. Pada dasarnya apabia perusahaan bisa memprediksi dengan tepat waktu sesuai dengan jumlah kebutuhan yang diinginkan, maka perusahaan dapat memungkinkan dengan persediaan sangat kecil atau bakan nol dengan menggunakan teknik persediaan just in time atau zero Inventory. Untuk memperediksi kebutuhan konsumen dengan tepat sangat sulit, hal ini karena kebutuhan konsumen yang fluktuasi, oleh karena itu setiap perusahaan perlu melakukan perencanaan persediaan dengan tepat agar tidak terjadi kelebihan atau kekurangan stock.

Economic Order Quantity (EOQ) merupakan suatu teknik untuk melakukan pengadaan persediaan bahan baku pada suatu perusahaan yang menentukan berapa jumlah pesanan yang ekonomis untuk setiap kali pemesanan dengan frekuensi yang telah ditentukan serta kapan dilakukan pemesanan kembali (Riyanto, 2001). Metode ini bertujuan untuk meminimalkan Total Inventory Cost. Penggunaan metode ini juga dapat menekan biaya-biaya persediaan sehingga efesiensi persediaan berjalan dengan baik dan dapat tercapai jumlah unit pemesanan yang optimal dengan menekan biaya seminimal mungkin. 


Penggunaan metode EOQ ini akan
mengasumsikan bahwa:
a. Tingkat permintaan barang diketahui
seragam secara konstan dan
berkelanjutan, maksudnya fluktuasi
permintaan barang relatif kecil.
b. Harga item sama untuk semua ukuran
pemesanan
c. Semua pesanan dikirim pada waktu
yang sama
Lead time konstan dan diketahui
dengan baik
Item merupakan produk tunggal dan
tidak ada kaitannya dengan produk lain
Biaya yang diperhitungkan adalah
biaya pemesanan dan biaya
penyimpanan
Menurut Heizer (2011) mengatakan
bahwa EOQ dapat dicari dengan rumus sebagai berikut:

$\mathrm{EOQ}=\sqrt{\frac{2 \times \mathrm{D} \times S}{\mathrm{H}}}$

Dengan:

$\mathrm{D}=$ Jumlah (dalam unit) yang dibutuhkan selama satu periode tertentu;

$\mathrm{S}=$ Biaya pesanan setiap kali pesan;

$\mathrm{H}=$ Harga penyimpanan per unit per tahun Untuk mengetahui frekuensi pengiriman dengan jumlah kuantitas pemesanan yang telah ditentukan maka dapat ditentukan dengan rumus :

$$
\mathrm{Fn}=\frac{\mathrm{D}}{\mathrm{Q}}
$$

Dengan :

$\mathrm{D}=$ Jumlah (dalam unit) yang dibutuhkan

selama satu periode tertentu

$\mathrm{Q}=$ Economic Order Quantity ( dalam unit)

\subsubsection{Reorder Point (ROP)}

Reorder Point (ROP) atau titik pemesanan kembali merupakan saat yang dilakukan untuk mengadakan pemesanan kembali produk atau bahan, sehingga pada saat penerimaan bahan yang dipesan tepat waktu sesuai dengan kapasitas yang diinginkan digudang. Bahan yang dipesan kembali perusahaan tiba pada saat persediaan bahan diatas Safety Stock atau sama dengan nol. Hal ini dilakukan agar persediaan digudang tidak melanggar Safety Stock (stock pengaman). Untuk menentukan ROP dapat digunakan rumus sebagai berikut :

$$
\mathrm{ROP}=(\mathrm{d} \times \mathrm{L})+\mathrm{SS}
$$

$\mathrm{d}$ = Tingkat kebutuhan;

$\mathrm{L}=$ Lead Time;

$\mathrm{SS}=$ Safety Stock

Pada suatu perusahaan menentukan maksimum persediaan yang disimpan harus diperhitungkan, karena mengingat kapasitas suatu gudang atau wharehouse tiap perusahaan pasti berbeda-beda. Maka untuk mengetahui besarnya persediaan yang maksimum untuk dilakukan penyimpanan dapat menggunakan rumus :

Dengan :

$$
\mathrm{MI}=\mathrm{Q}+\mathrm{SS}
$$

\section{MI = Maximum Inventory}

\subsubsection{Teknik Persediaan Just In Time (Metode Kanban) \\ Sistem produksi tepat waktu atau Jus} In Time merupakan sistem menejemen fabrikasi modern yang dikembangkan oleh perusahaan-perusahaan Jepang yang pada prinsipnya memproduksi jenis-jenis barang apa saja yang saat ini diperlukan dan dibutuhkan konsumen. Konsep Jus In Time pada persediaan bahan baku dimana bahan baku yang digunakan untuk aktivitas produksi didatangkan pemasok atau supplier tepat pada saat bahan tersebut di butuhkan pada proses produksi. Salah satu alat yang digunakan untuk merealisasikan sistem produksi Jus In Time adalah Kanban. Kanban atau biasa disebut pull system adalah sistem komunikasi atau kartu perintah yang digunakan untuk melakukan pemesanan bahan baku sesuai dengan kuantitas kebutuhan yang diinginkan, kuantitas sesuai dengan kapasitas persediaan untuk menghasilkan suatu produk.

Pada metode Kanban menuntuk adanya ketepatan waktu dan jumlah persediaan yang optimal guna menghindari terjadinya stockout maupun persediaan yang menumpuk. Metode ini sangat berbeda dengan metode EOQ.Untuk menentukan jumlah kartu Kanban pemasok dapat ditentukan dengan menggunakan rumus sebagai berikut :

$$
\mathrm{N}=\frac{\mathrm{dx}(\mathrm{c}+\mathrm{Wp}+\alpha)}{\mathrm{K}}
$$

Dengan :

$\mathrm{N}=$ Jumlah Kanban

$\mathrm{d}=$ Kebutuhan harian

$\mathrm{c}=$ Siklus pesanan

$\mathrm{Wp}=$ Waktu pemesanan

$\mathrm{K}=$ Kapasitas palet

$\alpha=$ Koefesien pengaman

Dengan : 
Untuk menentukan jumlah Kanban yang ekonomis, maka dibutuhkan:

1. Kebutuhan Harian

Dalam suatu perusahaan untuk memproduksi suatu produk maka perlu diketahui berapa jumlah kebutuhan per hari.

2. Frekuensi Pengiriman

Frekuensi pengirimian adalah jumlah pengirimian yang dibutuhkan dalam satu peridoer tertentu. Frekuensi pengiriman ini dapa dihitung dengan rumus sebagai berikut :

Dengan :

$$
\mathrm{fp}=\frac{\sum \mathrm{fb}}{\mathrm{K}}
$$

$\sum \mathrm{fb}=$ Jumlah pemesanan dalam satu periode

$\mathrm{K}=$ Kapasitas palet (dalam unit)

1. Siklus Pesan

Siklus pesan adalah putaran hari atau waktu yang digunakan untuk mengetahui kapan dilakukan pemesanankembali dan akan terjadi berulang. Siklus pesan ini dapat dicari dengan mengetahui jumlah hari kerja dalam satu periode, waktu tempuh pengiriman dari supplier menuju lokasi dan jumlah jam kerja selama satu hari. Langkah-langkah yang dapat dilakukan untuk menentukan siklus pesan adalah sebagai berikut :

1. Menentukan jumlah hari yangdigunakan untuk satu kali pesan dengan rumus sebagai berikut :

$\sum$ hari 1 kali pesan $=\frac{\sum \text { hari } \text { ker } j a}{\text { fp satu periode }}$

2. Menentukan waktu kirim dengan mengetahui jumlah jam kerja selama satu hari dan waktu tempuh supplier munuju lokasi dengan rumus sebagai berikut :

Waktu kirim $(\mathrm{Wk})=$ waktu tempuh supplier menju lokasi jumlah jam kerja 1 hari

Dengan demikian siklus pemesanan dapat dihitung dengan rumus sebagai berikut :

$$
\mathrm{c}=\frac{\|\mathrm{A}\|}{1}
$$

Dengan :

|| A || = Jumlah hari satu kali pesan - waktu kirim

2. Waktu Pemesanan

Pada metode Kanban waktu pemesanan seperti halnya dengan leadtime. Waktu pemesanan dapat dihitung dengan menggunkan rumus sebagai berikut :

Dengan :

$$
\mathrm{Wp}=\mathrm{c} \times \mathrm{C}
$$

$\mathrm{c}=$ siklus pesan
$\mathrm{C}=$ waktu pemuatan barang ke palet

3. Koefesien Pengaman

Koefesien pengaman adalah berapa banyak persediaan pengaman yang dapat digunakan dalam menentukan jumlah Kanban yang diinginkan. Biasanya koefesien pengaman dapat ditunjukkan dalam bentuk prosentasi.

4. Kapasitas Palet

Palet merupakan rak-rak yang berguna menyediakan penyimpanan bahan baku yang diinginkan. Kapasitas Palet adalah jumlah atau kuantitas bahan baku yang dapat ditampung rak-rak tersebut.Palet biasanya paling banyak digunakan perusahaan-perusahaan manufaktur. Keunggulannya adalah aksesibilitas tinggi sehingga metode FIFO (First In First Out) mudah dilakukan pada gudang bahan baku.

Total Inventory Cost (TIC) adalah hasil penjumlahan total dari biaya keseluruhan yang terkandung dalam persediaan selama satu periode. Biaya persediaan tersebut yaitu biaya penyimpanan, biaya pemesanan dan, biaya pembelian. TIC minimum akan terjadi pada tingkat pembelian yang ekonomis. TIC dapat dihitung dengan menggunakan rumus sebagai berikut :

$$
\mathrm{TIC}=(\mathrm{D} \times \mathrm{P})+\left(\frac{\mathrm{D} \times \mathrm{S}}{\mathrm{Q}}\right)+(\mathrm{I} \times \mathrm{H})
$$

Dengan :

$$
\begin{array}{ll}
\text { TIC } & \text { : Total Inventory Cost } \\
\text { D } & \text { : Permintaan } \\
\text { P } & \text { : Harga pembelian } \\
\text { Q } & \text { : Kuantitas pemesanan } \\
\text { S } & \text { : Biaya sekali pesan } \\
\text { I } & \text { : Inventory rata-rata } \\
\text { H } & \text { : Biaya simpan }
\end{array}
$$

2.4.2 Hubungan Total Inventory Cost (TIC), Ordering Cost (S) dan Holding Cost $(\mathrm{H})$

Dengan mengetahui hubungan TIC, Ordering Cost dan Holding Cost, maka dapat melakukan analisis EOQ, dimana analisis ini merupakan analisis yang cukup lemah dalam analisis keuangan.

\section{METODOLOGI PENELITIAN}

Objek penelitian ini adalah bahan baku produk AA-437 pada persediaan bahan baku di Warehouse PT Adyawinsa Stamping Industries

Penelitian dilakukan pada Departemen Material Planning Control di PT Adyawinsa Stamping Industries pada tanggal 10 Juli sampai dengan 10 Agustus 2017.

Data yang digunakan dalam penelitian ini diklasifikasikan sebagai berikut: 
1. Data permintaan order bahan baku produk AA-0437pada Bulan Juli 2016 sampai dengan Juni 2017 di departemen MPC pada PT Adyawinsa Stamping Industries.

2. Data lead time bahan baku produk AA-04377 selama Bulan Juli 2016 sampai dengan Juni 2017.

3. Data Safety Stock untuk bahan baku produk AA-0437, D30-717, dan AA417 di PT Adyawinsa Stamping Industries.

4. Nilai service level yang telah ditentukan perusahaan yaitu $95 \%$.

5. Data pembelian rata-rata bahan baku produk AA-0437 di PT Adyawinsa Stamping Industries.

6. Nilai koefisien pengaman yang diasumsikan oleh perusahaan adalah $5 \%$.

7. Data kapasitas palet masing-masing produk.

8. Data biaya pembelian, biaya simpan dan biaya pesan bahan baku produk AA-0437selama Bulan Juli 2016 sampai dengan Juni 2017.

9. Wawancara dan observasi kepada pihak terkait seperti staff asisten Manager di departemen MPC pada PT Adyawinsa Stamping Industries mengenai persediaan di gudang bahan baku.

Kerangka penelitian adalah suatu cara untuk menentukan langkah - langkah yang akan dilakukan. Adapun langkah - langkah tersebut dapat dilihat pada Gambar 3.1

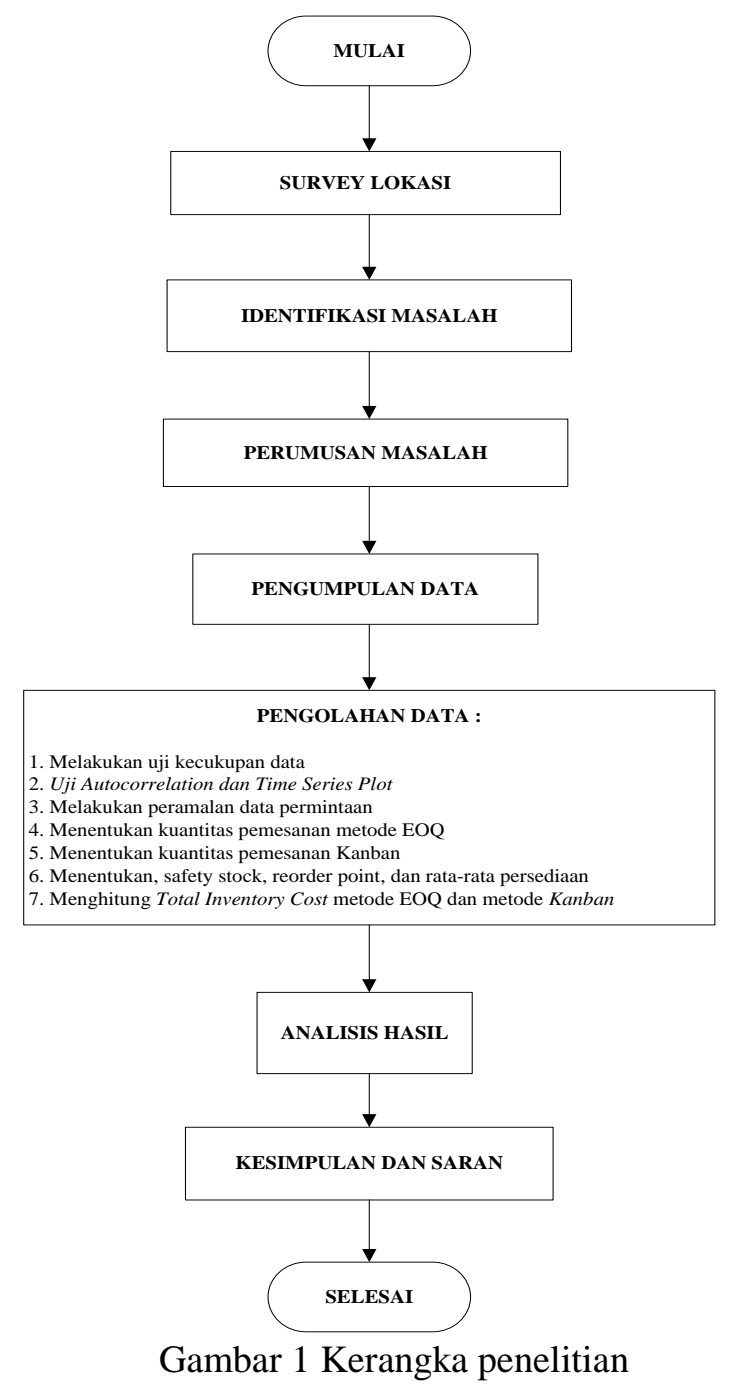

\section{Pengolahan Data}

Beberapa tahapan pengolahan data yang dilakukan :

1. Menghitung total kebutuhan bahan baku produk dan menghitung kebutuhan bahan baku harian.

2. Mengitung uji kecukupan data untuk kebutuhan bahan baku produk.

3. Menentukan dan melakukan perhitungan metode peramalan menggunakan software WinQSB.

4. Menghitung biaya-biaya persediaan.

5. Menghitung kuantitas pemesanan, Safety Stock, Reorder Piont, stok persediaan maksimal dan stok persediaan rata-rata.

6. Pada metode Kanban menghitung jumlah Kanban yang dibutuhkan, kuantitas untuk satu Kanban, stok persediaan maksimal dan stok persediaan rata-rata tiap produk.

7. Mengkomprarasi Total Inventory Cost metode EOQ dan metode Kanban. 
8. Membandingkan metode EOQ, Kanban dan metode yang ada di perusahaan.

9. Menganalisis dan memberikan saran terhadap metode yang terpilih.

\section{PEMBAHASAN}

Data kapasitas palet bahan baku produk AA-437 adalah 600 unit. Sedangkan tabel data permintaan bahan baku produk AA-437 pada bulan Juli 2016- Juni 2017 yang dapat dilihat pada Tabel 4.1

Tabel 4.1 data permintaan produk AA-437

\begin{tabular}{|l|c|}
\hline \multirow{2}{*}{ Bulan } & Permintaan (D) \\
\cline { 2 - 2 } & 58371-BZ130 (AA-0437) \\
\hline Jul-2016 & 4860 \\
\hline Agu-2016 & 9670 \\
\hline Sep-2016 & 6750 \\
\hline Okt-2016 & 6930 \\
\hline Nov-2016 & 7200 \\
\hline Des-2016 & 6840 \\
\hline Jan-2017 & 7866 \\
\hline Feb-2017 & 7380 \\
\hline Mar-2017 & 4688 \\
\hline Apr-2017 & 7760 \\
\hline Mei-2017 & 10560 \\
\hline Jun-2017 & 8550 \\
\hline Jumlah & 94488 \\
\hline Rata-rata & 7874 \\
\hline Standar.Dev & 2211,052 \\
\hline
\end{tabular}

Data biaya persediaan untuk bahan baku produk AA-437 sebagai berikut : Pembelian material : Rp 10.925,00 per unit Biaya Pemesanan: Rp 200.000,00 per pesan Biaya Simpan : Rp 5.456,00 per unit/tahun

Faktor pengali dari nilai service level, perusahaan mengasumsikan kepuasan user sebanyak 95\% maka berdasarkan ketentuan nilai faktor pengalinya adalah 1,64 yang dapat dilihat pada Tabel 4.2.

Tabel 4.2 Faktor pengali dari service level

\begin{tabular}{|c|c|}
\hline Service Level & Faktor Pengali \\
\hline $\mathbf{9 9 , 9 \%}$ & 3,09 \\
\hline $\mathbf{9 9 , 5 \%}$ & 2,58 \\
\hline $\mathbf{9 9 \%}$ & 2,33 \\
\hline $\mathbf{9 7 \%}$ & 1,88 \\
\hline $\mathbf{9 6 \%}$ & 1,75 \\
\hline
\end{tabular}

\begin{tabular}{|l|l|}
\hline $\mathbf{9 5 \%}$ & 1,64 \\
\hline $\mathbf{9 0 \%}$ & 1,28 \\
\hline
\end{tabular}

(Sumber: Titus, 2013)

Pengujian kecukupan data ini diperlukan untuk mengetahui apakah data yang digunakan sudah mencukupi atau belum. Berdasarkan hasil pengumpulan data permintaan bahan baku produk AA-437, maka diperoleh pengolahan data pada Tabel 4.3.

Tabel 4.3 Pengolahan Data produk AA-437

\begin{tabular}{|c|c|c|}
\hline \multirow{2}{*}{ No. } & \multicolumn{2}{|c|}{ Permintaan (D) } \\
\cline { 2 - 3 } & $\mathrm{X}$ & $\mathrm{X}^{2}$ \\
\hline 1 & 4860 & 23619600 \\
\hline 2 & 9670 & 93508900 \\
\hline 3 & 6750 & 45616516 \\
\hline 4 & 6930 & 48024900 \\
\hline 5 & 7200 & 43877376 \\
\hline 6 & 6840 & 52490025 \\
\hline 7 & 7866 & 61873956 \\
\hline 8 & 7380 & 59721984 \\
\hline 9 & 4688 & 29214025 \\
\hline 10 & 7760 & 60217600 \\
\hline 11 & 10560 & 136328976 \\
\hline 12 & 8550 & 143280900 \\
\hline Total & 94488 & 797774758 \\
\hline Rata-Rata & 7874 & 66481229,83 \\
\hline
\end{tabular}

Dengan tingkat ketelitian $15 \%$ sehingga $\mathrm{s}=0,15$ dan tingkat keyakinan $\mathrm{k}=$ 1,65. Banyaknya data $(\mathrm{N})$ sebesar 12 . Maka didapatkan uji keseragaman data sebagai berikut :

$$
\begin{aligned}
& \mathrm{N}^{\prime}=\left[\frac{\frac{k}{s} \sqrt{n \Sigma t^{2}-(\Sigma t)^{2}}}{\Sigma t}\right]^{2} \\
& \mathrm{~N}^{\prime}=\left[\frac{\frac{1,65}{0,15} \sqrt{12(797774758)-(94488)^{2}}}{94488}\right]^{2} \\
& \mathrm{~N}^{\prime}=8,75
\end{aligned}
$$

Dari perhitungan di atas didapatkan bahwa $\mathrm{N}^{\prime}<\mathrm{N}$ maka dapat dikatakan bahwa data pengamatan yang digunakan sudah cukup. 4.2.2 Uji Autocorrelation dan Time Series Plot

Dalam menentukan metode peramalan apa yang dapat digunakan sebaiknya melakukan uji autocorrelation dan time series plot terlebih dahulu. Uji autocorrelation dapat dilihat pada gambar 4.1 sebagai berikut: 


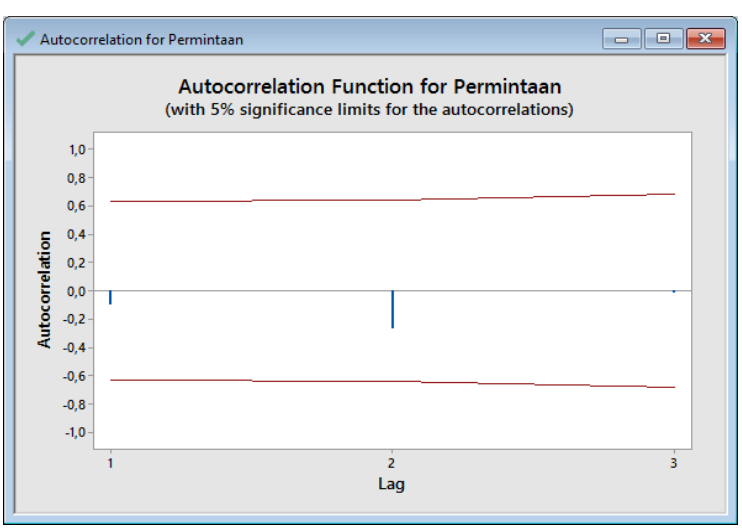

Gambar 2 Uji autocorrelation pada bahan baku produk AA-437

Berdasarkan gambar diatas, dapat dilihat bahwa nilai ACF berada diantara $0.5<\mathrm{ACF}<0.5$ maka dengan data tersebut dapat dilakukan peramalan dengan menggunakan time series. Sedangkan untuk time series plot dapat dilihat pada Gambar 4.2.

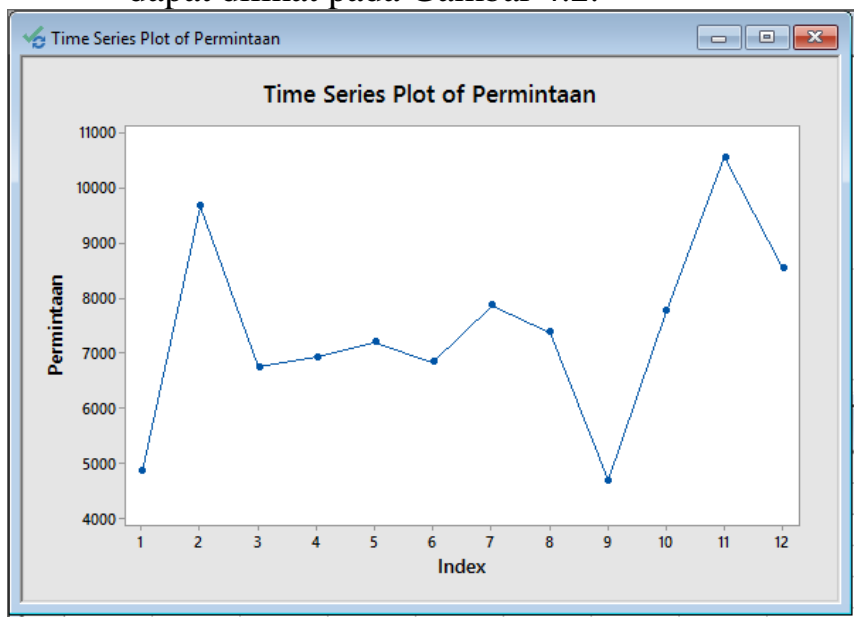

Gambar 3 Time series plot pada permintaan

$$
\text { AA- } 437
$$

Dari gambar diatas dapat dilihat bahwa data teresebut berpola trend. Sehingga dapat dilakukan peramalan dengan metode yang sesuai.

Metode yang digunakan dalam pengendalian dalam mengoptimalkan persediaan adalah :

Dalam melakukan perencanaan, perusahaan perlu melakukan peramalan untuk mengantisipassi dan merencanakan tindakan untuk kedepannya. Berdasarkan peramalan yang dilakukan dengan menggunakan software Minitab 16 denga melihat pola data maka digunakan 3 buah metode yaitu : metode Single Exponential Smoothing with Trand (SEST), metode Deouble Exponential Smoothing with Trand (SEST) atau metode Holt-Winters Additive Algorithm (HWA). Berikut merupakan data hasil ringkasan yang didapatkan dari ketiga metode tersebut pada Tabel 4.4.

Tabel 4.4 Hasill Ringkasan Erorr

\begin{tabular}{|c|l|c|c|c|}
\hline No. & Metode & Periode & MAD & MSE \\
\hline 1. & Metode SEST & 12 & 1449,839 & 5011490 \\
\hline 2. & Metode DEST & 12 & 1671,852 & 5168480 \\
\hline 3. & Metode HWA & 12 & 1250,061 & 4150003 \\
\hline
\end{tabular}

Berdasarkan data diatas, metode peramalan hyang dipilih adala metode HoltWinters Additive Algorithm dengan nilai MAD sebesar 1250,061. Hasil peramalan metode ini dapat dilihat pada Tabel 4.5.

Tabel 4.5 Hasil peramlan metode HWA

\begin{tabular}{|l|c|}
\hline \multirow{2}{*}{ Bulan } & Permintaan Peramalan (D) \\
\cline { 2 - 2 } & 58371-BZ130 (AA-0437) \\
\hline Jul-2017 & 8847 \\
\hline Agu-2017 & 9114 \\
\hline Sep-2017 & 9381 \\
\hline Okt-2017 & 9648 \\
\hline Nov-2017 & 9916 \\
\hline Des-2017 & 10184 \\
\hline Jan-2018 & 10451 \\
\hline Feb-2018 & 10719 \\
\hline Mar-2018 & 10986 \\
\hline Apr-2018 & 11253 \\
\hline Mei-2018 & 11521 \\
\hline Jun-2018 & 11788 \\
\hline Jumlah & 123808 \\
\hline Rata-rata & 10317,33333 \\
\hline Standar.Dev & 964,220 \\
\hline
\end{tabular}

Pada penelitian ini bertujuan untuk mengetahui kuantitas pemesanan yang paling ekonomis. Berikut merupakan perhitungan untuk bahan baku AA-0437 dengan menggunakan metode EOQ :

$$
\begin{array}{r}
Q=\sqrt{\frac{2 \times S \times D}{H}} \\
= \\
\sqrt{\frac{2 \times 200000 \times 123808}{5456}} \\
=3013 \text { unit }
\end{array}
$$

Berikut ini merupakan perhitungan frekuensi pengiriman bahan baku AA-437 : Fn $=\frac{D}{Q}=\frac{123808}{3013}=42 \mathrm{kali} /$ periode

Waktu siklus pemesanan $=\frac{248}{42}=6$ hari

Jadi berdasarkan jumlah perhitungan diatas di peroleh jumlah kuantitas pemesanan bahan baku AA-437 yang paling ekonomis 
sebesar 3013 unit dengan frekuensi pengiriman sembanyak 42 kali dalam satu tahun, dengan waktu siklus pemesanan adalah 6 hari.

2. Menentukan jumlah SafetyStock

Dalam menentukan Safety Stock perlu diketahui nilai dari standar deviasi penggunaan bahan baku dasar. Perusahaan telah mengasumsikan service level 95\%. Sehingga kemungkinan kehabisan persediaan sebesar $5 \%$.

Berikut ini merupakan perhitungan standar deviasi untuk bahan baku AA-437 :

$\operatorname{Std}=\sqrt{\frac{(x-\bar{x})^{2}}{N-1}}=964,22$

Setelah didapatkan nilai standart deviasi maka dengan nilai lead time sebesar 1 hari Safety Stock dapat dihitung dengan rumus

$\mathrm{SS}=$ Service Level $\mathrm{x}$ std $\mathrm{x} \mathrm{L}$

$$
=(1,64 \times 964,22 \times 1)
$$

$=1582$ unit

3. Menentukan saat pemesanan kembali atau Reoder Point

Menentukan jumlah dari ROP untuk bahan baku AA-437 sebagai berikut :

$$
\begin{aligned}
\mathrm{ROP} & =(\text { demand harian } \times \mathrm{LT})+\mathrm{SS} \\
& =(505 \times 1)+1582 \\
& =2087 \text { unit }
\end{aligned}
$$

4. Menentukan Maximum Inventory (MI)

Pada bahan baku produk AA-437 didapatkan Maximum Inventory sebagai berikut :

$$
\begin{aligned}
\text { MI } & =\mathrm{Q}+\mathrm{SS} \\
& =3013+1582 \\
& =4595 \text { unit }
\end{aligned}
$$

5. Menentukan Rata-rata tingkat Inventory (I)

Pada bahan baku produk AA-437 didapatkan rata-rata tingkat Inventory sebagai berikut :

$$
\begin{aligned}
& \mathrm{I}=\mathrm{SS}+\left(\mathrm{Q} \times \frac{1}{2}\right) \\
&= 1582+\left(3013 \times \frac{1}{2}\right) \\
&= 3088 \text { unit } \\
& \quad \text { Pada perhitungan metode Kanban }
\end{aligned}
$$
menggunakan sistem Kanban pemasok. Kanban adalah kartu perintah atau sistem komunikasi yang digunakan untuk melakukan kuantitas pemesanan sesuai dengan kapasitas persediaan yang dibutuhkan untuk menghasilkan suatu produk. Pada metode ini menuntut adanya ketepatan waktu dan jumlah persediaan guna menghindari penumpukan persediaan di gudang.
Dalam menentukan kebutuhan harian data yang digunakan adalah data hasil peramalan. Kebutuhan harian tersebut dapat dilakukan dengan menggunakan rumus :

$$
\mathrm{d}=\frac{\sum \text { kebutuhan bulanan }}{\sum \text { hari kerja }}
$$

Tabel 4.6 Jumla permintaan harian

\begin{tabular}{|l|c|c|}
\hline \multicolumn{1}{|c|}{ Bulan } & $\begin{array}{c}\text { Jumlah Hari } \\
\text { Kerja }\end{array}$ & $\begin{array}{c}\text { Jumlah Permintaan } \\
\text { Harian AA-437 }\end{array}$ \\
\hline Jul-2016 & 15 & 590 \\
\hline Agu-2016 & 22 & 415 \\
\hline Sep-2016 & 22 & 427 \\
\hline Okt-2016 & 22 & 439 \\
\hline Nov-2016 & 25 & 397 \\
\hline Des-2016 & 20 & 510 \\
\hline Jan-2017 & 20 & 523 \\
\hline Feb-2017 & 20 & 536 \\
\hline Mar-2017 & 20 & 550 \\
\hline Apr-2017 & 20 & 563 \\
\hline Mei-2017 & 21 & 549 \\
\hline Jun-2017 & 21 & 562 \\
\hline Jumlah & 248 & 6061 \\
\hline Rata-rata & - & 505 \\
\hline
\end{tabular}

Dengan mengetahui total kebutuhan tahunan dan kapasitas palet, selanjutnya dapat menghitung frekuensi pengiriman bahan baku produk AA-437 :

$$
\begin{aligned}
\mathrm{Fp} & =\frac{\sum f b}{K} \\
& =\frac{123808}{600} \\
& =207 \mathrm{kali} / \mathrm{tahun}
\end{aligned}
$$

Jumlah hari yang digunakan untuk 1 kali pesan untuk bahan baku produkAA-437 sebagai berikut :

$$
\begin{aligned}
\text { Produk AA-437 } & =\frac{\sum \text { hari ker } j a}{f p 1 \text { tahun }} \\
& =\frac{248}{207} \\
& =1,312
\end{aligned}
$$

Waktu kirim (Wk) untuk semua produk adalah sebagai berikut :

Dengan 1 hari $=8$ jam kerja $=8 \times 60^{\prime}=480^{\prime}$

Untuk waktu tempuh dari lokasi supplier menuju lokasi perusahaan $=3$ jam $=3$ x $60^{\prime}=180^{\prime}$

$$
\mathrm{Wk}=\frac{180 \prime}{480 \prime}=0,375
$$

Setelah mengetahui waktu pesan dan waktu kirim maka didapatkan siklus pemesanan bahan baku produk AA-347 : 


$$
\begin{aligned}
c & =\frac{\|A\|}{B} \\
& =\frac{\|1,312-0,375\|}{1} \\
& =1 \text { hari }
\end{aligned}
$$

Untuk menentukan waktu siklus dibutuhkan waktu pemuatan barang ke palet (C) adalah 30 menit dibagi jumlah waktu kerja yaitu 480 menit. Sehingga didapatkan Wp bahan baku produk AA-437 :

$$
\begin{aligned}
\mathrm{Wp} & =\mathrm{c} \times \mathrm{C} \\
& =1 \times \frac{30 \prime}{480 \prime} \\
& =0,0625 \text { hari }
\end{aligned}
$$

Penentuan koefesien pengaman telah ditentukan perusahaan sebesar $5 \%$.

Menentukan jumlah kartu Kanban untuk masing-masing produk dengan rumus sebagai berikut :

Pada produk AA-437 :

$$
\begin{aligned}
\mathrm{N} & =\frac{d x(c+W p+a)}{K} \\
& =\frac{505 x(1+0,0625+0,05)}{600} \\
& =0,937 \approx 1 \text { kartu Kanban }
\end{aligned}
$$

Jumlah pemasanan adalah jumlah kuantutas pemesanan $=1 \times 600$

$$
=600 \text { unit }
$$

Pada bahan baku produk AA-437 didapatkan Safety Stock dan rata-rata tingkat Inventory sebagai berikut :

$$
\begin{aligned}
\text { SS } & =\text { Service Level } \times \text { std } \times \mathrm{L} \\
& =1,64 \times 67 \times 1 \\
& =110 \text { unit } \\
\mathrm{I} & =\mathrm{SS}+\left(\mathrm{Q} \times \frac{1}{2}\right) \\
& =110+\left(600 \times \frac{1}{2}\right) \\
& =410 \text { unit }
\end{aligned}
$$

Setelah mengetahui Inventory rata-rata dan kuantitas pemesanan tiap masingmasing metode, maka dapat menghitung Total Inventory Cost (TIC) untuk metode EOQ, metode Kanban dan metode yang ada diperusahaan.

1. Total Inventory Cost untuk metode EOQ

Menentukan TIC untuk bahan baku produk AA-437 :

$$
\begin{aligned}
& \mathrm{TIC}=(\mathrm{D} \times \mathrm{P})+\left(\frac{\mathrm{D} \times \mathrm{S}}{\mathrm{Q}}\right)+(\mathrm{I} \times \mathrm{H}) \\
& =(123808 \times 10.925)+ \\
& \left(\frac{123808 \times 200.000}{3013}\right)+(3088 \times 22) \\
& =\mathrm{Rp} 1.377 .668 .782,00
\end{aligned}
$$

2. Total Inventory Cost untuk metode Kanban
Menentukan TIC untuk bahan baku produk AA-437 :

$$
\begin{aligned}
\mathrm{TIC} & =(\mathrm{D} \times \mathrm{P})+\left(\frac{\mathrm{D} \times \mathrm{S}}{\mathrm{Q}}\right)+(\mathrm{I} \times \mathrm{H}) \\
& =(123808 \times 10.925)+ \\
\left(\frac{123808 \times 200.000}{600}\right)+(410 \times 22) & + \\
& =\text { Rp } 1.396 .108 .693,00
\end{aligned}
$$

3. Total Inventory Cost untuk metode di perusahaan

Menentukan TIC untuk bahan baku produk AA-437 :

$$
\begin{aligned}
\mathrm{TIC} & =(\mathrm{D} \times \mathrm{P})+\left(\frac{\mathrm{D} \times \mathrm{S}}{\mathrm{Q}}\right)+(\mathrm{I} \times \mathrm{H}) \\
& =(123808 \times 10.925)+ \\
\left(\frac{123808 \times 200.000}{900}\right)+(764 \times 22) & + \\
& =\text { Rp } 1.380 .132 .097,00
\end{aligned}
$$

Berikut merupakan hasil perhitungan Total Inventory Cost untuk bahan baku produk AA-437 yang dapat dilihat pada Tabel 4.7.

Tabel 4.7 TIC untuk produk AA-0437

\begin{tabular}{|c|c|c|}
\hline \multicolumn{3}{|c|}{ 58371-BZ130 (AA-0437) } \\
\hline EOQ & Kanban & Perusahaan \\
\hline Rp 1.377.668.782 & $\operatorname{Rp~1.396.108.693~}$ & Rp 1.380.132.097 \\
\hline
\end{tabular}

Berdasarkan hasil perhitungan ini maka dapat dinyatakan bahwa metode EOQ paling baik dibandingkan metode Kanban mapun metode yang ada diperusahaan. Hal ini dapat dilihat pada biaya pesan bahan baku produk AA-437 dengan frekuensi pemesanan sebanyak 42 kali maka total biaya per periode Rp 8.400.000,00. Sedangkan untuk metode Kanban frekuensi pemesanan sebanyak 207 kali maka total biaya per periode $\mathrm{Rp}$ 41.400.000.

Dengan menggunakan metode EOQ dapat diperoleh kuantitas pemesanan paling ekonomis untuk bahan baku produk AA-437 sebesar 3013 unit, Safety Stock 1582 unit, ROP sebesar 2087 unit, maximum inventory sebesar 4595 unit dan rata-rata tingkat inventory sebesar 3088 unit. Degan adanya titik pemesanan kembali dan diketahuinya persediaan pengaman yang optimal maka dapat mengantisipasi kekosongan bahan baku jikat terjadi keterlambatan bahan baku. Sedangkan dengan menggunakan metode Kanban dapat diketahui untuk komponen porduk AA-437 memerlukan 1 kartu Kanban dengan kuantitas pemesanan sebesar 600 unit, Safety stock sebesar 110 unit dan rata-rata tingkat Inventory sebesar 410 unit.

Pada Total Inventory Cost, untuk metode yang ada diperusahaan menghasilkan 
TIC sebesar Rp 1.380.132.097,00. Dari perhitungan Total Inventory Cost, apabila menerapkan metode EOQ maka didapatkan TIC sebesar $\mathrm{Rp}$ 1.377.668.782,00, apabila perusahaan memilih metode Kanban makadidapatkan TIC sebesar Rp 1.396.108.693,00. Dari metode EOQ, metode Kanban, dam metode yang ada diperusahaan dapat dilihat bahwa yang memberikan nilai Total Inventory Cost minumum untuk bahan baku produk AA-437adalah metode EOQ. Apabila metode EOQ ini diterapkan diperusahaan maka dapat menghemat sebesar Rp 2.463.315,00. Sedangkan untuk metode Kanban dan metode yang ada diperusahaan dari Total Inventory Cost menunjukkan bahwa metode di perusahan lebih baik diterapkan daripada metode Kanban. Hal ini dapat mengendalikan persediaan pada gudang bahan baku agar tidak terjadi kekurangan stock, akan tetapi apabila perusahaan menerapkan metode EOQ, maka diperlukan perluasan area gudang bahan baku atau mengatur dan menyusun kembali penempatan bahan baku, untuk menampung persediaan tambahan tiap komponen.

\section{KESIMPULAN}

Berdasarkan pengolahan data dan analisis hasil yang telah dilakukan, dapat diambil kesimpulan sebagai berikut:

a. Frekuensi pembelian bahan baku apabila menggunakan metode EOQ adalah 42 kali dengan kuantitas pemesanan sebesar 3013 unit, sedangkan menggunakan metode Kanban adalah 207 kali dengan kuantitas pemesanan sebesar 600 unit.

b. Metode EOQ memberikan kuantitas pemesanan yang paling optimal dengan mengeluarkan biaya per periode pada bahan baku produk AA437 sebesar Rp 1.377.668.782,00 sedangkan untuk metode Kanban sebesar Rp 1.396.108.693,00.

c. Apabila metode EOQ ini diterapkan diperusahaan maka penghematan untuk bahan baku produk AA-437 sebesar Rp 2.463.315,00. Sedangkan perbandingan metode Kanban dan metode yang ada diperusahaan dari Total Inventory Cost menunjukkan bahwa metode di perusahan lebih baik diterapkan daripada metode Kanban. d. Persediaan pengaman apabila menggunakan metode EOQ sebesar 1582 unit sedangkan menggunakan metode Kanban sebesar 110 unit.

e. Rata-rata tingkan persediaan apabila menggunakan metode EOQ adalah 3088 unit, sedangkan menggunakan metode Kanban adalah 410 unit.

Setelah dilakukan perhitungan dengan menggunakan metode pengendalian persediaan yaitu metode EOQ dan metode Kanban pada PT Adyawinsa Stamping Industries, maka penulis mengajukan saran yang dapat dijadikan bahan pertimbangan dalam kebijakan pengadaan bahan baku produk AA-437. Adapun saran-saran tersebut adalah sebagai berikut:

a. Perusahaan sebaiknya meninjau kembali kuantitas pemesanan yang ekonomis agar tidak terjadi kelebihan maupun kekurangan stock.

b. Perusahaan sebaiknya meninjau kembali waktu pemesanan bahan baku agar tidak terjadi keterlambatan pada saat memporduksi.

c. Perusahaan sebaiknya mengatur penempatan atau penyusunan gudang bahan baku untuk menanggulangi stock tambahan, sehingga pada saat stock dibutuhkan maka proses produksi tidak terganggu.

d. Beberapa kekurangan yang terdapat dalam penelitian ini diharapkan dapat dikembangkan lebih lanjut melalui penelitian-penelitian selanjutnya.

\section{DAFTAR PUSTAKA}

Assauri, Sofyan, 1999, Manajemen Produksi dan Operasi, LPFE-UI : Jakarta.

Griffin, Ricky W, 2004, Manajemen. Erlangga : Jakarta.

Heizer, Jay dan Barry Render, 20011, Operations Management, Buku 1 edisi ke Sembilan, Salemba empat: Jakarta

Herjanto, Eddy, 2009, Sains Manajemen Analisis Kuantitatif untuk Pengambilan Keputusan, Grasindo : Jakarta.

Mahardhika Arga, dkk., 2013, “Analisis Perbandingan Pengendalian dengan Pendekatan Metode Economic Order Quantity dan Metode Kanban", Student Journal, Hal.454-463 vol. 10, jrmsi.studentjournal.ub.ac.id (diakses pada 27 Juli 2017 pukul 12.48 WIB). 
Margaretha, Farah, 2007, Manajemen Keuangan bagi Industri Jasa, Grasindo : Jakarta.

Nasution, A. H., dan Prasetyawan, Y, (2008), Perencanaan \& Pengendalian Produksi, Edisi Pertama, Graha Ilmu : Yogyakarta.

Prawirosentono, 2005, Riset Operasi Dan Ekonofisika. Penerbit PT Bumi Aksara: Jakarta.

Margaretha, Farah, 2007, Manajemen Keuangan bagi Industri Jasa, Grasindo : Jakarta. 